\title{
MIXED RESPONSES TO THE PUBLICATION OF PREVENTION GREEN PAPER
}

The British Society of Paediatric Dentistry (BSPD) and the national Community Water Fluoridation (CWF) network have reacted positively to the publication of the Green Paper 'Advancing our health: prevention in the 2020s' in late July, but the British Dental Association (BDA) has described its eleventh-hour publication as a 'fire sale' and challenged the incoming government not to turn its back on evidence-based policy making.

The consultation document published by the Cabinet Office and the Department of Health and Social Care commits to rolling out more tooth brushing schemes in nurseries and schools in England. The stated aim is to consult on proposals for supervised toothbrushing to reach $30 \%$ of the most deprived 3-5-year-olds by 2022 .

BSPD spokesperson Claire Stevens said: 'Investing in oral health prevention instead of spending millions of pounds on the management of dental decay is the smart way forward and an approach which we hope the incoming Prime Minister will fully support'.

BSPD were also delighted that the Green Paper is committed to water fluoridation, a feeling echoed by the CWF network. 'Advancing our health: prevention in the 2020s' says that the NHS should work more closely with local authorities to implement water fluoridation schemes, sharing some of the ensuing savings achieved thanks to a reduced spend on the treatment of dental decay.

Simon Hearnshaw, who is spearheading the national CWF network, said that if half the money saved on dental treatment was to be shared with local authorities, this would more than cover the recurring costs of water fluoridation.

The BDA, however, expected the Green Paper to form the 'cornerstone of the government's strategy for the NHS'. In addition to its policies on supervised tooth brushing and water fluoridation, it includes pledges to ban sales of energy drinks to under-16s, expansion of the sugar levy, and further action of childhood obesity.

BDA Chair Mick Armstrong said: 'A Green Paper setting out big ideas to finally put prevention into practice now looks more like a fire sale.

'The tragedy is this document contains numerous tried-and-tested policies, which could save children from pain and our NHS millions in treatment costs.

'In the rush to avoid the charge of "Nanny Statism" the first casualty cannot be evidence-based policymaking. Health professionals will look to the next government to show leadership, and will not let this process be swept under the carpet.'

\section{References}

1. Open consultation. Advancing our health: prevention in the 2020s. 22 July 2019. Available at: https://www.gov.uk/ government/consultations/advancingour-health-prevention-in-the-2020s (accessed August 2019).

\section{LETTER}

\section{PRAISE FOR PRACTICE PRINCIPALS}

Dear BDJ Team,

I am a lead dental nurse working in a private dental practice in Leigh on Sea, Essex. I would like my practice principals to have some recognition for their continued dedication to supporting the wellbeing of their staff members.

At our practice we facilitate students studying dental hygiene/therapy. We also currently offer diabetes screening to patients who are at risk of diabetes. This service has also been offered to staff members (if they wish to take part) and many of us have been screened. I am very pleased to report none of the staff members who took part are high risk, but it has heightened our awareness of which factors contribute to type 2 diabetes.

It has been requested in staff meetings that if our practice principals wish to buy the staff biscuits/cakes to help with staff morale can there now be a healthier option/ alternative. Consequently, our practice principals have now provided a fruit bowl

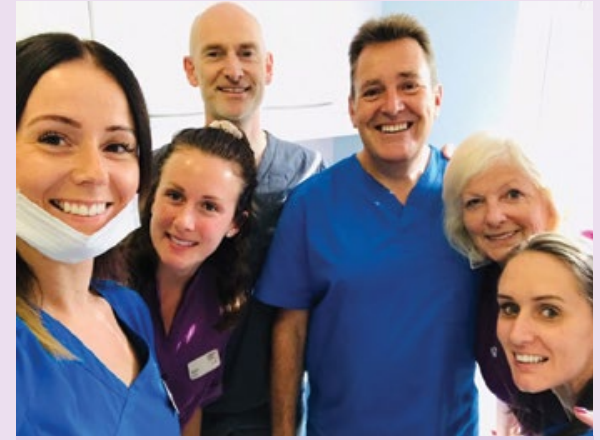

Pictured from left to right: Sarah, Remi (nurse), Professer Phillip Cannell (principal dentist), Richard Metcalf (principal dentist), Lyn (practice manager), Debbie (nurse)

in the staff room which is filled with fresh fruit weekly. It seems to have been a big hit with the staff members. We are now also being provided with alternative milk options to enjoy in our tea and coffees, not forgetting our herbal tea options.

I think you will agree that our principals have gone above and beyond for their staff members by helping us to lead and maintain a healthy lifestyle. In my personal opinion I think staff who are healthy are also happy so I think the practice will greatly benefit from this.

Sarah Smith,

Lead RDN, Chalkwell Dental Practice, Leigh on Sea

\section{Write to us}

Do you have an opinion on something published in BDJ Team or on working in the dental industry? Do you need advice from an expert that we might be able to help you with? Just email bdjteam@nature.com.

Letters may be edited for space. Opinions expressed do not necessarily reflect those of the editorial team or the publishers.

https://doi.org/10.1038/s41407-019-0158-7 